\title{
Effect of Vinasse Recycling on Effluent Reduction from Distilleries: Case of Metehara Distillery, Ethiopia
}

\author{
Ayele Alemu ${ }^{1, *(\mathbb{D}}$, Minale Getachew ${ }^{2}$, Gulam Mohammed Sayeed Ahmed ${ }^{2,3}\left(\mathbb{D}\right.$, Vineet Tirth ${ }^{4,5}$ \\ and Ali Algahtani ${ }^{4,5}$ (D)
}

1 Sugar Technology and Engineering Research Program, Research and Development Center, Sugar Corporation, Wonji 15, Ethiopia

2 Mechanical Engineering Department, Adama Science and Technology University, Adama 1888, Ethiopia; minalegz@gmail.com (M.G.); gmsayeed.ahmed@astu.edu.et or drgmsa786@gmail.com (G.M.S.A.)

3 Center of Excellence (COE) for Advanced Manufacturing Engineering, Adama Science and Technology University, Adama 1888, Ethiopia

4 Mechanical Engineering Department, College of Engineering, King Khalid University, Abha 61421, Saudi Arabia; vtirth@kku.edu.sa (V.T.); alialgahtani@kku.edu.sa (A.A.)

5 Research Center for Advanced Materials Science (RCAMS), King Khalid University, Guraiger, P.O. Box 9004, Abha 61413, Saudi Arabia

* Correspondence: aylkas15@gmail.com

check for updates

Citation: Alemu, A.; Getachew, M.; Ahmed, G.M.S.; Tirth, V.;

Algahtani, A. Effect of Vinasse

Recycling on Effluent Reduction from

Distilleries: Case of Metehara

Distillery, Ethiopia. Processes 2022, 10,

7. https://doi.org/10.3390/

pr10010007

Academic Editor: Davide Dionisi

Received: 3 November 2021

Accepted: 29 November 2021

Published: 22 December 2021

Publisher's Note: MDPI stays neutral with regard to jurisdictional claims in published maps and institutional affiliations.

Copyright: (c) 2021 by the authors. Licensee MDPI, Basel, Switzerland. This article is an open access article distributed under the terms and conditions of the Creative Commons Attribution (CC BY) license (https:// creativecommons.org/licenses/by/ $4.0 /)$.

\begin{abstract}
This study was conducted at the ethanol plant of Metehara sugar factory, at a laboratory scale, to assess the effect of recycling vinasse into the fermentation process on effluent reduction. Vinasse is an effluent produced from distilleries. The experimental design included vinasse concentrations at 4 dilution rates ( 0 (control), 20, 35, 50, and 65\% of process water) with 2 replicates and 6 responses, as follows: ethanol yield, fermentation efficiency, residual sugar concentration, cell count, cell viability, and calcium oxide content. In this study, the actual operational parameters of the ethanol plant were maintained during the experiment. The result of the experiment indicates that, with up to $20 \%$ vinasse recycling, there was no influential impact on the ethanol yield, the fermentation efficiency, the residual sugar concentration, or the calcium oxide content, attributable to the recycling, as compared to the control. Above $20 \%$ vinasse recycling, ethanol yield and fermentation efficiency decreased sharply from those of the control. In addition, with $20 \%$ vinasse recycling put into practice, the amount of vinasse generated will be reduced by about $19.5 \%$ and about 114.2 tons of water will be saved per day. Moreover, the excess amount of vinasse produced by the distillery, which is beyond the handling capacity of bio-compost plant of the distillery, will reduce from 105 to 36.8 tons per day. Therefore, it is possible to recycle vinasse into the fermenter up to $20 \%$ on dilution water of Metehara distillery, without causing any impacts on the distillery's performance.
\end{abstract}

Keywords: distillery effluent; vinasse; recycling; molasses fermentation; ethanol production

\section{Introduction}

Ethanol is widely used as fuel for IC (internal combustion) engines, blended with gasoline. Nowadays, it has become an alternative energy source to alleviate the fuel shortage. It is an eco-friendly fuel, with relatively lower greenhouse gas emissions than petroleum-based fuels [1]. A feedstock commonly used for bio-ethanol production is molasses, which is one of the by-products of the sugar industry. It contains mainly noncrystallizable residue that is disposed of as by-product during recovery of crystal sugar. Some of the advantages of using molasses as a raw material for ethanol production are the following: it is available in abundant quantities, it is a relatively inexpensive feedstock, and it does not require hydrolysis of starch [2].

Fermentation is the common method used to produce ethanol from molasses. Ethanol can be produced with various grades from molasses. Ethanol production from sugarcane molasses is carried out by three important processes, i.e., molasses treatment, fermentation, 
and distillation. However, the heart of the ethanol production system is the fermentation process, since the other processes are used for raw material preparation and for the separation of the manufactured products [3].

The mineral composition of sugarcane substrate varies; it is dependent on sugarcane variety, sugarcane maturity, climate, soil conditions, the processing of sugarcane into juice, and the proportion of the molasses used to formulate the media [4].

Vinasse is an effluent produced from distilleries and it is one of the most difficult wastes to dispose of. This is due to the fact that the volume of vinasse that is generated is high; typically, one liter of alcohol produced from molasses-based ethanol distilleries generates 8-15 $\mathrm{L}$ of vinasse. It has high temperature, a low $\mathrm{pH}$, a high ash content, a dark brown color, and a high percentage of dissolved organic and inorganic matters [5-8]. Vinasse also has substantial value as a source of potash; therefore, it can be returned to the fields where the cane was cultivated, using the existing sugarcane irrigation system. Irrigation is the simplest and cheapest method. However, care must be taken not to overload the soil, otherwise, excessively high buildups of both organic and inorganic component levels may occur, resulting in salt accumulation and a fall-off in the cane yield $[3,5,6,9]$.

Evaporating the vinasse to obtain concentrated effluent is another method of handling the effluent. The concentrated effluents reduce the quantity of the vinasse and hence transfer costs to outlying fields. However, the high capital cost of stainless-steel evaporators, the need to clean with aggressive chemicals, and the additional steam required, generally makes this an unfavorable option. It is also possible to evaporate the vinasse in large, shallow ponds, using solar energy. Application of a spray drying system, preceded by evaporation, is also used to produce a concentrated feed for animals $[3,5,9]$. Residual stream, obtained after evaporating the vinasse, can also be used as a fuel for stillage-fired boilers, which can be used to produce energy in excess of distilleries' requirements [6].

Anaerobic fermentation of vinasse produces methane as a by-product, which is a feasible method of handling the effluent. The gas produced can be used as a fuel to supplement the fuel required for ethanol plants. However, the required anaerobic reactors are large and cumbersome. The effluent from the anaerobic digester still requires further treatment, since it has a high chemical oxygen demand (COD) content: about 113,000 mg/L with molasses as a feedstock, for disposal, or for reuse [3,5,6,9].

To reduce the effluent generated during ethanol production from distilleries, it is also possible to produce yeast from vinasse. However, the high cost of production makes this alternative an unfavorable option [5,9].

Adding the vinasse to filter cakes-which are one of the by-products of the cane sugar industry - on large concrete slabs, is used to produce compost. Very good quality compost, high in potash, is produced within about 30 days [3]. This option has been used by the Metehara distillery; however, the quantity of vinasse produced is beyond the handling capacity of the bio-compost plant. This study was initiated with the aim to devise a method of handling the excess vinasse that is produced by the distillery.

Metehara Sugar Factory (MSF) is located $200 \mathrm{~km}$ from the capital Addis Ababa, Ethiopia, in the southeast direction. The factory was constructed by a Dutch company called HVA (Handelsvereniging Amsterdam), in a joint venture with the Ethiopian Government, and started production in 1962. The ethanol plant of the MSF start production in 2011 with annual production capacity of 12.5 million liter. The plant produces $28 \mathrm{~m}^{3} / \mathrm{h}$ of fermented wash, using 4 continuously stirred tank reactors, arranged in series. The amount of concentrated vinasse, process condensate, and spent lees generated by the plant are about 350, 236, and 87.4 tons/day, respectively. The bio-compost plant of the factory has a capacity to handle 245 tons of concentrated vinasse per day, and the remaining concentrated vinasse is accumulated in the pond for later use.

Recirculation of the vinasse back to the fermenters, alike to dilution water, has been proposed as an option for reducing the volume of vinasse generated. However, studies 
revealed that the presence of inhibitors, such as acetic acid, limits the practical applications of vinasse recirculation [10].

Several consultants recommended that the factory should use the distillery effluent in the place of dilution water in the fermentation section. According to them, it is possible to use all effluent generated from the rectifier column-which is called spent lees-and process the condensate from the vinasse-concentrating evaporator as a source of dilution water in the fermenter. They also stated that it is possible to recirculate about $50 \%$ of the spent wash that is generated, back into the fermentation plant. In addition, to reduce effluent generation from distilleries, back sloping can be carried out in the fermentation station, with the view of improving $\mathrm{pH}$ to controlling bacteria growth, the nutrients needed by the yeast for rapid growth, the buffering action of the fermented wash, and the utilization of process water and steam ([11] p. 19). For a typical sugar cane molasses feed, the inhibitory effects would not be observed if vinasse recycling was limited to a maximum of one-third of the feed rate [12]. Studies conducted at Egyptian distilleries revealed that vinasse generated from the fermentation of sugarcane molasses can be recycled safely up to $50 \%$ for ethanol production in distilleries, without causing any significant differences in either ethanol yield or fermentation efficiency [13]. Fresh water consumption of a distillery is reduced with vinasse recycling. It can be reduced further, if the liquid fraction of the vinasse is recycled after it is separated from the vinasse [14].

The vinasse generated during the production of ethanol can be a serious source of water pollution. However, it is also possible to recover useful by-products from the vinasse, such as animal feed, fertilizer, and methane gas. Therefore, production of by-products from vinasse can be a valuable resource $[3,5,9]$. The selection of an optimum vinasse management system is a trade-off between economic, energy, and environmental considerations [9].

By comparison, $10-20 \%$ of mash volume is typically recycled in commercial final molasses fermentation; however, $30 \%$ recycled volume is reported to adversely affect productivity [12]. However, studies focusing on effect of vinasse recycling on effluent reduction in the case of the Metehara distillery have not yet studied in literature for practical applicability.

The MSF produces about 350 tons/day of concentrated vinasse, while its bio-compost plant has the capacity to handle 245 tons/day. Handling and proper treatment of the excess vinasse is a problem; hence, the factory accumulates the remaining in the pond for later use. In addition, during storage, the vinasse undergoes different chemical and biological reactions and produces a pungent smell. Handling excess vinasse is a big problem for the factory, because if the excess vinasse overflows the pond, it will become a big threat to the environment. Therefore, this study aiming to assess the effect of recycling vinasse as a fermenter on effluent reduction, through an experimental study for the case of the MSF.

\section{Materials and Methods}

The experiment was conducted at the MSF ethanol plant, using a laboratory-scale experimental setup. The experiments were carried out in 2 replicates and the treatment involved the recycling of vinasse at 4 percentage dilution rates ( 0 (control), 20, 35, 50 and $65 \%$ of dilution water), assessing 6 responses: the ethanol yield, the fermentation efficiency, the residual sugar concentration, the cell count, the cell viability, and the calcium oxide content. A total of 10 runs were conducted with 2 replications. In this study, the operational parameters of the ethanol plant are used in the experiment.

Sugarcane molasses produced by the MSF were taken and analyzed in the laboratory. The molasses were used without any pretreatment in this research.

A study conducted to assess the capability of the yeast strains to produce ethanol showed that all the strains produced an almost similar percentage of ethanol $(9.2 \% v / v)$ during both laboratory- and pilot-scale demonstrations [15]. Therefore, the strain used by the ethanol plant was used during this laboratory-scale experiment. The distillery uses a strain of baker's yeast (Saccharomyces cerevisiae) [16]. Molasses, diluted with water, was used as a medium, to culture the yeast strain. The water that was used for dilution was 
blended with vinasse at different concentrations $(0,20,35,50$, and $65 \%$ of the total volume) to study the effect of vinasse recycling on effluent reduction.

During media preparation, $100 \mathrm{gm}$ molasses was taken into a $1000 \mathrm{~mL}$ beaker and $565 \mathrm{~mL}$ water was added to obtain 14 Brix, then $1 \mathrm{gm}$ urea and $0.5 \mathrm{gm}$ DAP were added. The media was sterilized for $1 \mathrm{~min}$ at boiling point, and after cooling to $30^{\circ} \mathrm{C}$, the $\mathrm{pH}$ was adjusted to 4.3 using $98 \%$ concentrated sulfuric acid. A measure of $500 \mathrm{~mL}$ media was taken into a $1000 \mathrm{~mL}$ Erlenmeyer flask, then $125 \mathrm{~mL}$ of culture was added, and it was incubated for $24 \mathrm{~h}$. The fermentation was carried out at $33^{\circ} \mathrm{C}, 4.3 \mathrm{pH}$, and 7.94 reduced sugar concentration. The same procedure was used during the vinasse test, except that the percentage of water for the dilution of the molasses changed to $20,35,50$, and $65 \%$ of vinasse, instead of water.

In this study, vinasse was collected from the ethanol plant of the MSF. Then it was used at 20,35, 50, and $65 \%$ to prepare the fermentation medium. After fermentation, the obtained fermented wash was boiled in a $1000 \mathrm{~mL}$ beaker for each concentration, and stirred at $700 \mathrm{rpm}$ until the alcohol percentage dropped below $0.2 \%$.

The vinasse obtained from fermentation process was used for recycling tests, equivalent to $20,35,50$, and $65 \%$ of the water of the dilution for the following fermentation.

A rapid method was used to the determine sugar concentration of the feed (sugarcane molasses). A measure of $5 \mathrm{~mL}$ of fermented sample was taken and dissolved in $100 \mathrm{~mL}$ of distilled water, mixed with $5 \mathrm{~mL}$ of concentrated $\mathrm{HCl}$ acid $(98 \%)$, and was heated at $70{ }^{\circ} \mathrm{C}$ for a period of $10 \mathrm{~min}$. The obtained samples were neutralized by adding $\mathrm{NaOH}$, prepared up to $1000 \mathrm{~mL}$, and transferred into a burette solution. A measure of $5 \mathrm{~mL}$ of Fehling A and $5 \mathrm{~mL}$ of Fehling B were taken and mixed with $10-15 \mathrm{~mL}$ of distilled water in a conical flask, then methylene blue indicator was added. The conical flask solution was titrated with burette solution in boiling conditions until the blue color disappeared. The total fermentable sugar in gm/1-which is sugar concentration-was calculated using the following formula:

Total fermentable sugar $=($ Dilution factor $\times$ Fahling factor $/$ Titrate volume $) \times 100$,

where the Fehling factor is the quantity of invert sugar in grams required to completely reduce the Fehling solution (usually $5 \mathrm{~mL}$ of both Fehling A and B solutions).

An Ebulliometer (Electronic Ebulliometer BLUTEH 2000, Star Zagora, Bulgaria) was used to measure ethanol yield of the fermented samples (yield) in $\% v / v$. The theoretical yield is calculated as follows [16]:

$$
\text { Theoretical ethanol yield }=\text { Total fermentable sugar } \times 0.64 \text {. }
$$

Fermentation efficiency in \% (FE) was determined as the percentage of actual ethanol yield for each of the vinasse concentrations, in relation to the theoretical ethanol yield [17].

$$
\text { Fermentation efficiency }=\text { Ethanol yield } / \text { Theoretical ethanol yield } \times 100 \text {. }
$$

Reducing sugar (RS) consists primarily, but not exclusively, of glucose and fructose, and was obtained through the hydrolysis of sucrose. Reducing sugar, measured in \%, was measured according to the Lane and Eynon method using Fehling solution, as per SASTA, 2005. The percentage reducing sugars in the sample was calculated as indicated below:

$$
\text { Reducing sugar }=\mathrm{MRS} /(10 \times \mathrm{MJ}) \text {, }
$$

where MRS is the mass of reducing sugar (mg) in $100 \mathrm{~cm}^{3}$ and MJ is mass of juice (g) in $100 \mathrm{~cm}^{3}$.

Cell count (CC) was determined using a microscope, with the help of a Haemocytometer. Methylene blue indicator was used to check cell viability. The dead cells were stained with the blue indicator, while viable cells remained uncolored. 
Cell viability in $\%(\mathrm{CV})$ is determined using the following relation:

$$
\text { Cell viability }=\text { Viable cell } / \text { Total number of cell } \times 100 \text {. }
$$

In heat transfer equipment of the Metehara distillery, it has been observed that scale formation rate is rapid and due to which the distilleries and evaporator units serve for shorter period and must be cleaned frequently. So, due to frequent cleaning of the equipment, production halted. Recycling of vinasse may aggravate the situation by recirculating scale-causing compounds back to the fermenter. Therefore, measuring the $\mathrm{CaO}$ content of the vinasse produced at each vinasse concentration level can be used to examine the effect of vinasse recycling on the formation of scales on heat transfer surfaces. Studies have reported that mineral salts are not assimilated by yeast [12].

$\mathrm{CaO}$ content in the vinasse was determined by using complexometric titration against EDTA solution [18].

All experiments were carried out in two replicates, and all reported data were given in mean values. Significances and standard deviation were calculated using the analysis of variance (ANOVA) using Version 7.0.0 software ( $p$-value $<0.05$ ). The response variables of the experiment were evaluated with reference to the control (with no recycled vinasse).

\section{Results}

The effect of vinasse recycling on ethanol fermentation was tested in molasses medium at different vinasse concentrations and results are presented below. The results of the laboratory experiment, analyzing different vinasse concentrations, are tabulated in Tables 1 and 2.

Table 1. Effect of vinasse concentration on yield, FE, and RS.

\begin{tabular}{cccc}
\hline Vinasse (\%) & Yield (\%) & FE (\%) & RS (\%) \\
\hline 0 & 9.58 & 88.92 & 1.90 \\
20 & 9.55 & 88.78 & 1.78 \\
35 & 8.80 & 82.31 & 1.81 \\
50 & 7.64 & 71.80 & 1.92 \\
65 & 7.08 & 66.06 & 2.23 \\
\hline
\end{tabular}

Table 2. Effect of vinasse concentration on CC, CV. and $\mathrm{CaO}$ content.

\begin{tabular}{cccc}
\hline Vinasse (\%) & CC & CV (\%) & CaO (ppm) \\
\hline 0 & $2.95 \times 10^{8}$ & 86.37 & 2135.30 \\
20 & $2.78 \times 10^{8}$ & 83.51 & 2181.20 \\
35 & $2.72 \times 10^{8}$ & 85.42 & 2324.70 \\
50 & $2.5 \times 10^{8}$ & 76.84 & 2548.56 \\
65 & $2.1 \times 10^{8}$ & 70.88 & 2801.12 \\
\hline
\end{tabular}

\subsection{Effect of Vinasse Concentration on Yield, Fermentation Efficiency, and Residual Sugar}

The fermentation process was conducted with $0,20,35,50$, and $65 \%$ vinasse concentrations to study the effect of vinasse recycling on ethanol production; the results are shown in Table 1. Ethanol yield was $9.58 \%$ without vinasse, which was used as the control. The result indicated that the ethanol yield decreased from 9.55 to $7.08 \%$ as vinasse concentration increased from 20 to $65 \%$ (Figure 1a).

The effects of FE during vinasse recycling at different percentages in water are also presented in Table 1. It was found that the fermentation efficiency ranged between 66.06 and $88.92 \%$. The results indicate that fermentation efficiency decreased sharply as vinasse concentration increased.

Residual sugar concentration (RS) was measured and is also tabulated in Table 1. The results indicate that the RS value slightly increased as concentration of vinasse increased from 20 to $50 \%$. However, the RS value increased sharply once vinasse concentration was above $50 \%$. The value of RS was found to be between 1.8 and $2.2 \%$. 


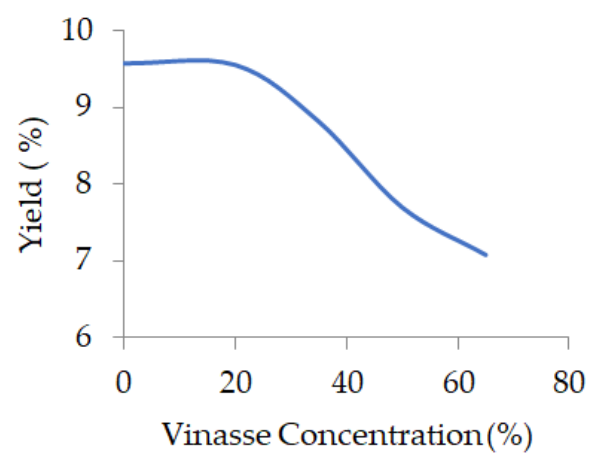

(a)

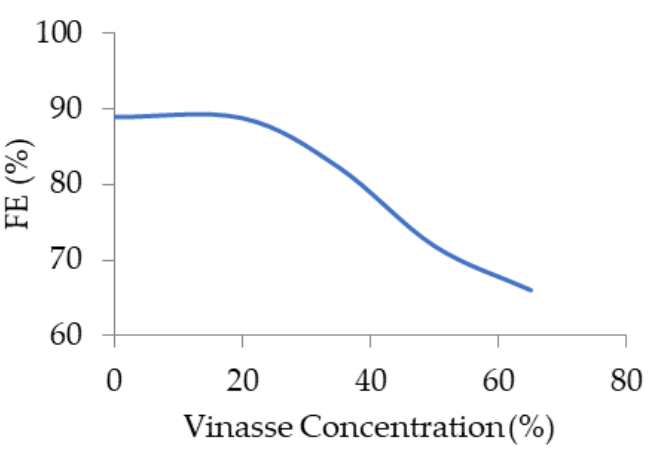

(b)

Figure 1. (a) Effect of vinasse concentration on yield. (b) Effect of vinasse concentration on FE.

\subsection{Effect of Vinasse Concentration on Cell Count, Cell Viability, and Calcium Oxide Content}

Vinasse was recycled at different concentrations for molasses dilution to prepare a fermentation medium, and the results concerning cell count and cell viability are tabulated in Table 2. During the experiment, it was found that cell count ranged between $2.78 \times 10^{8}$ and $2.1 \times 10^{8}$ and cell viability ranged between 84.38 and $73.33 \%$, within 20 to $65 \%$ vinasse recycling, respectively. The result indicates that cell count decreased continuously as the percentage of vinasse recycling increased. Whereas cell viability decreased slightly, up to $35 \%$ concentration; however, after 35\% concentration, it decreased shapely.

The fermentation process of molasses, supplemented with various vinasse recycling rates concentrations, revealed that calcium oxide concentration increased as the concentration of vinasse recycling increased. The $\mathrm{CaO}$ content was $2135.3 \mathrm{ppm}$, without vinasse recycling using fresh water for dilution, and this value was taken as a reference for comparison. It was noted that an increase in the vinasse recycling resulted in an increase in $\mathrm{CaO}$ content concentration from 2181.2 to $2801.12 \mathrm{ppm}$.

\section{Discussion}

Ethanol yield decreased slightly from 9.58 to $9.55 \%$ as vinasse concentration increased from 0 to $20 \%$. Above $35 \%$ of vinasse, ethanol yield decreased sharply as the concentration of vinasse increased. The effects of vinasse on ethanol yield depended on its concentration $[10,13]$. Castro and Gil [19] stated that the presence of inhibitors, such as solids and acetic acid, limit the recirculation percentage and the number of recycles possible. Thus, the reason behind the decrease in ethanol productivity may be an increase in soluble solids and inhibiters in the medium. In this study, it was found that the highest yield (9.55) was obtained at $20 \%$ vinasse, and there was no significant difference with the control.

The fermentation efficiency decreased as vinasse concentration increased. It was found that the highest fermentation efficiency (88.78) was obtained at $20 \%$ vinasse, and there was no significant difference from the control. The result obtained by Fadel et al. (2014) [13] showed that up to $30 \% v / v$ vinasse, replacing water, has no effect on fermentation efficiency. Rein [3] mentioned that molasses has to be diluted to keep dissolved solids concentrations at levels low enough that fermentation is not affected by a high osmotic pressure.

The amount residual sugar after fermentation is important. The residual sugar increased with an increase in vinasse concentration; however, RS increased sharply above a vinasse concentration of $50 \%$. The RS value was between 1.8 and $2.2 \%$, which is in good agreement with the findings of similar studies, which show values between 1.9 and $2.5 \%$, with respect to concentrations of $20-60 \%$ vinasse [13].

In this study, the result indicates that cell viability increases slightly from 20 to $35 \%$; however, after 35\%, it decreases sharply. Less than one-third of the bleed could be recycled before $\mathrm{Ca}^{2+}$ inhibition would reduce cell production by $20 \%$ [12]. A study showed that osmotic stress has impact on yeast population dynamics. It is caused by great amounts of salts present in sugarcane molasses [4]. Reduction in cell viability may be attributed to salt 
concentration increasing as vinasse concentration increases in the mediums, which, in turn, results in increased osmotic pressure.

The percentage of $\mathrm{CaO}$ contents increased sharply after $20 \%$ of vinasse, as shown in Table 2. This indicates that the $\mathrm{CaO}$ content in the fermentation media increased during recycling of vinasse at different rates, with respect to the vinasse concentration percentage. The osmotic stress, caused by salts, is a matter of concern; additionally, high levels of calcium, potassium, and magnesium found in the substrate may substantially exceed the requirements for yeast nutrition [4].

A study conducted at an ethanol plant indicated that the $\mathrm{CaO}$ content of the scale samples taken from the distillation column of the factory was 63.87\% [20] (pp. 36-38). Vinasse recycling must be limited to a maximum of one-third of the feed rate for a typical sugarcane molasses feed [12]. The percentage of increase in $\mathrm{CaO}$ content as shown in Figure 2, up to $20 \%$ vinasse recycling, was below $5 \%$, which is $2.15 \%$.

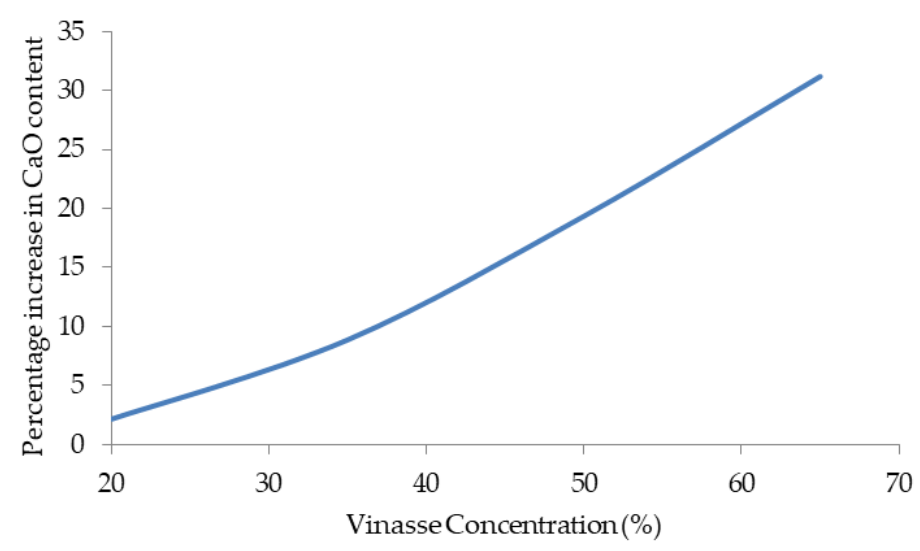

Figure 2. Percentage of $\mathrm{CaO}$ content as a function of vinasse concentration.

In this study, it was found that the maximum yield achieved in the case of vinasse recycling was $9.55 \%$, which was obtained at $20 \%$. It was also found that the maximum FE $(88.78 \%)$ was obtained at the same vinasse concentration. Hence, both yield and FE have no significant difference from the control, if the concentration of vinasse was kept within the $20 \%$ range (Figure $1 \mathrm{a}, \mathrm{b}$ ). Besides, the $\mathrm{CaO}$ content was the lowest at $20 \%$ vinasse.

Based on the findings of this study, $20 \%$ vinasse concentration can be recycled to the fermenter instead of process water; water savings were calculated based on $20 \%$ recycled vinasse. It was found that there was a proportional reduction in water consumption, with about a 19.5\% (68.2 ton/day) reduction in vinasse volume. Without vinasse recycling, the excess vinasse generated is 105 ton/day; however, with $20 \%$ vinasse recycling, it will be reduced to 38.6 ton/day, as shown in Table 3. The treatment cost will also reduce, accordingly, during compost preparation. The total reduction amount of vinasse is within the range specified by similar studies [10].

Therefore, the total amount of vinasse reduction will be 114.2 ton/day, only by using $20 \%$ of vinasse for molasses dilution. Based on the process layout of the factory, vinasse can be recycled from the primary column re-boiler to the fermenter: the process flow diagram is shown in Figure 3. In order to increase the amount of vinasse recycled to above $20 \%$ and reduce excess vinasse, further study should be carried out by treating the molasses. Moreover, after this successful laboratory-scale experiment, it is vital to harness the benefits of the findings of the research by implementing the vinasse recycling at the ethanol plant of the MSF. 
Table 3. Water balance with $20 \%$ vinasse recycling.

\begin{tabular}{ccc}
\hline Operating Parameter & & Capacity (ton/Day) \\
\hline Molasses & & 206 \\
Process water & 571 \\
Vinasse supplied to the evaporator & 586 \\
Concentrated vinasse \% of supplied & & 59.73 \\
vinasse & Without recycling & 245 \\
Bio-compost capacity & - & With recycling \\
Recycled amount (20\% of process water) & 586 & 114.2 \\
Net amount to be evaporated & 350 & 471.8 \\
Amount of concentrated vinasse & - & 281.8 \\
Reduction of concentrated vinasse & & $68.2(19.5 \%)$ \\
\hline
\end{tabular}

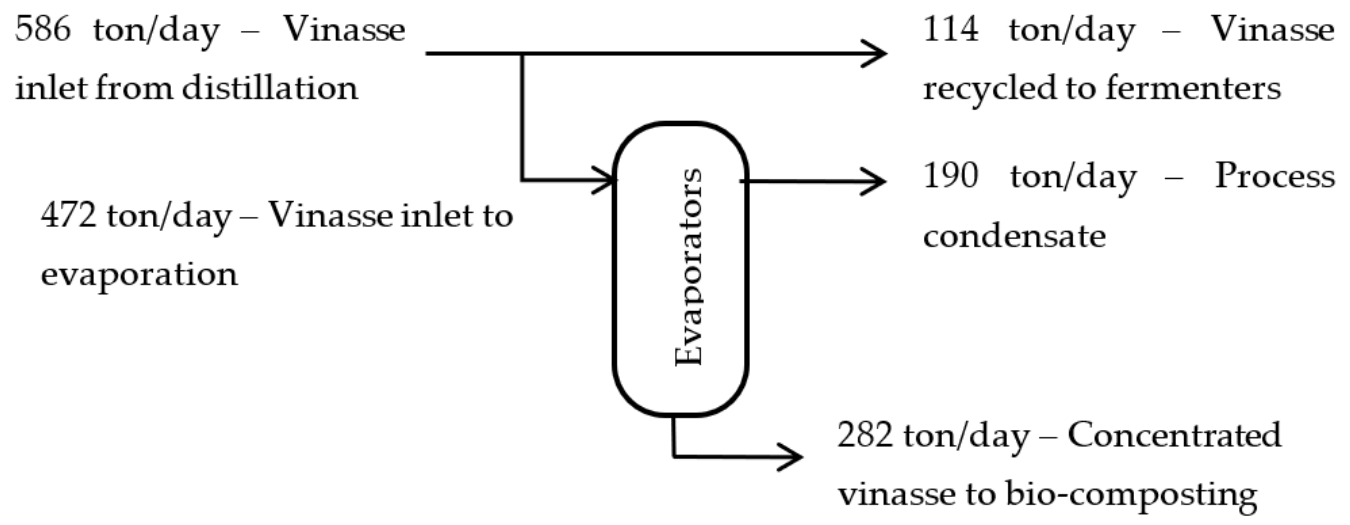

Figure 3. Mass balance of the evaporation plant with vinasse recycling.

\section{Conclusions}

The fermentation of molasses by recycling vinasse at different concentrations indicated that $20 \%$ vinasse dilution rate results in $9.55 \%$ ethanol yields and $88.78 \%$ fermentation efficiency at the operating conditions of the Metehara distillery. The effect of $20 \%$ recycled vinasse on sugarcane molasses fermentation indicated that yield and fermentation efficiency had no significant difference from the control. With the $20 \%$ recycled vinasse, 114.2 tons of fresh water was saved per day, and the amount of vinasse volume generated decreased by $19.5 \%$ ( 68.2 ton/day). The excess amount of vinasse, beyond the handling capacity of the bio-compost plant of the distillery, also decreased from 105 to 36.8 tons/day. The study showed that up to $20 \%$ vinasse can be used instead of fresh water for ethanol production, without causing significant effects on either ethanol yield or fermentation efficiency. It is also indicated that the $\mathrm{CaO}$ content of the vinasse increased sharply above $20 \%$ recycling.

Author Contributions: A.A. (Ayele Alemu), conceptualization; A.A. (Ayele Alemu) and M.G., methodology; A.A. (Ayele Alemu) and G.M.S.A., software; A.A. (Ayele Alemu) and M.G., validation; A.A. (Ayele Alemu), formal analysis; A.A. (Ayele Alemu) and M.G., investigation; A.A. (Ayele Alemu), resources; A.A. (Ayele Alemu), writing-original draft preparation; M.G. and G.M.S.A., writing—review and editing; G.M.S.A., visualization; A.A. (Ayele Alemu), supervision; A.A. (Ali Algahtani), project administration; V.T. and A.A. (Ali Algahtani), funding acquisition. All authors have read and agreed to the published version of the manuscript.

Funding: The authors gratefully acknowledge the Deanship of Scientific Research, King Khalid University (KKU), Abha-Asir, Saudi Arabia, for funding this research work under the grant number RGP.2/58/42.

Institutional Review Board Statement: Not applicable.

Informed Consent Statement: Not applicable. 
Data Availability Statement: The data presented in this study are available on request from the corresponding author.

Acknowledgments: The authors extend their appreciation to the Research and Development Center of Sugar Corporation, Ethiopia, for technical expertise and financial assistance in carrying out experiments. The authors gratefully acknowledge the Deanship of Scientific Research, King Khalid University (KKU), Abha-Asir, Saudi Arabia, for funding this research work under the grant number RGP.2/58/42.

Conflicts of Interest: The authors declare no conflict of interest.

\section{References}

1. Amin, R.M.; Hossain, S.M.; Sarker, M. Simulation of Ethanol Production by Fermentation of Molasses. J. Eng. (JOE) 2013, 1, 69.

2. Patrascu, E.; Rapeanu, G.; Bonciu, C.; Hopulele, T. Bio-Ethanol Production from Molasses by Different Strains of Saccharomyces Cerevisiae. In Fascicle VI-Food Technology, Proceedings of the International Symposium Euro-Aliment 2009, 9-10 October 2009; Galati University Press: Galati, Romania, 2009; p. 49.

3. Rein, P. Cane Sugar Engineering; Verlas Dr. Albert Bartens KG: Berlin, Germany, 2007; pp. 726-731.

4. Basso, L.C.; Basso, T.O.; Rocha, S.N. Ethanol Production in Brazil: The Industrial Process and Its Impact on Yeast Fermentation. In Biofuel Production-Recent Developments and Prospects; Dos Santos Bernardes, M.A., Ed.; IntechOpen: London, UK, 2011 ; pp. 88-92.

5. Christofoletti, C.A.; Escher, J.P.; Correia, J.E.; Marinho, J.F.U.; Fontanetti, C.S. Sugarcane Vinasse: Environmental Implications of Its Use. Waste Manag. 2013, 33, 2754-2758. [CrossRef] [PubMed]

6. Olguin, E.J.; Doelle, H.W.; Mercado, G. Resource Recovery through Recycling of Sugar Processing By-products and Residuals. Resour. Conserv. Recycl. 1995, 15, 90-92. [CrossRef]

7. Ansari, F.; Awasthi, A.K.; Srivastava, B.P. Physico-chemical Characterization of Distillery Effluent and Its Dilution Effect at Different Levels. Arch. Appl. Sci. Res. 2012, 4, 1705-1706.

8. Mikucka, W.; Zielińska, M. Distillery Stillage: Characteristics, Treatment, and Valorization. Appl. Biochem. Biotechnol. 2020, 192, 772-773. [CrossRef] [PubMed]

9. Willington, I.P.; Marten, G.G. Options for Handling Stillage Waste from Sugar-Based Fuel Ethanol Production. Resour. Conserv. 1982, 8, 111-129. [CrossRef]

10. Castro, G.A.; Caicedo, L.A. Reduction of Stillage's Volume in the Production of Ethanol by Recirculation Applying Liquid-Liquid Extraction. Available online: http://www.nt.ntnu.no/users/skoge/prost/proceedings/ecce6_sep07/upload/3292.pdf (accessed on 15 February 2020).

11. Mirkena, B. Optimization of Molasses Fermentation to Ethanol to Reduce Effluent Generation: The Case of Metahara Sugar Factory. Master's Thesis, Addis Ababa University, Addis Ababa, Ethiopia, 2014.

12. Maiorella, B.L.; Blanch, H.W.; Wilke, C.R. Feed and Component Inhibition in Ethanol Fermentation. Biotechnol. Bioeng. 1984, 26, 1155-1166. [CrossRef] [PubMed]

13. Fadel, M.; Zohri, A.A.; Makawy, M.; Hsona, M.S.; Abdel-Aziz, A.M. Recycling of Vinasse in Ethanol Fermentation and Application in Egyptian Distillery Factories. Afr. J. Biotechnol. 2014, 13, 4390-4397. [CrossRef]

14. Gumienna, M.; Lasik, M.; Szambelan, K.; Czarnecki, Z. Reduction of Water Consumption in Bioethanol Production from Triticale by Recycling the Stillage Liquid Phase. Acta Sci. Pol. Technol. Aliment 2011, 10, 473.

15. Fakruddin, M.; Quayum, M.; Ahmed, M.M.; Choudhury, N. Analysis of Key Factors Affecting Ethanol Production by Seccharomyces Cerevisiae. Biotechnology 2012, 11, 251.

16. Gasmalla, M.A.A.; Yang, R.; Nikoo, M.; Man, S. Production of Ethanol from Sudanese Sugar Cane Molasses and Evaluation of Its Quality. J. Food Process. Technol. 2012, 3, 1-3.

17. Hamed, I.H.; Hussein, N.N.; Hekmat, R.M.; Salem, S.A.; Nour, S.E. Statistical Optimization of Batch Ethanol Fermentation of Sugarcane Molasses by Candida Tropicalis Strain HSC-24. Int. J. ChemTech Res. 2015, 8, 2.

18. Kassa, H. Handbook of Laboratory Methods and Chemical Control for Ethiopian Sugar Factories; Ethiopian Sugar Development Agency Research Directorate: Wonji, Ethiopia, 2009; pp. 63-65.

19. Castro, G.A.; Gil, I.D. Development of an Ethanol Production Process with Stillage Recycling at Pilot Plant-Scale. Available online: http:/ / www.nt.ntnu.no/users/skoge/prost/proceedings/ecce6_sep07/upload/3561.pdf (accessed on 15 February 2020).

20. Firdissa, T. Design and Optimization of Molasses Treatment to Reduce Scale Formation in Ethanol Production (The Case of Metahara Sugar Factory Ethanol Plant). Master's Thesis, Addis Ababa University, Addis Ababa, Ethiopia, 2012. 